\title{
Bone Fractures Produced by High Velocity Impacts '
}

\author{
DONALD F. HUELKE, LYNN J. BUEGE, AND JAMES H. HARGER \\ Department of Anatomy, The University of Michigan, \\ Ann Arbor, Michigan
}

\begin{abstract}
The effects of high velocity impact to the distal end of 122 human femurs were studied using one-quarter inch steel spheres as projectiles, with impact velocities from 500 to 1700 feet per second. In the lower velocity range, a "drill hole" fracture was produced with low energy expenditure, and the diameter of this type of fracture was increased as a function of increasing velocity. At the higher impact velocities the bone exploded with a violent radial displacement of the material surrounding the missile path, similar to the cavitation effect often seen in soft tissues. At increasing impact velocities, increasing amounts of energy were expended in producing the fracture.
\end{abstract}

Although there have been many experimental studies on the effects of high velocity impacts to animals or animal tissues (Dziemian et al., '61; Harvey et al., '47; Harvey and McMillen, '47; and Krauss, '57), only a few have been concerned primarily with bone (Horsley, 1894; Keith and Hall, '19; and Grundfest, '45). The literature on the effects of high velocity impacts has been summarized in Wound Ballistics (Coates and Beyer, '62), an outstanding compilation and review of the pertinent studies in this field.

Most studies have dealt with the response of soft tissues to high velocity impacts. In these studies tissue damage has been attributed to not only the direct impact of the projectile but also to the rapid radial displacement of the tissues. As the projectile passes through the tissue, radial displacement of the tissue about the path of the projectile produces a temporary cavity of very short duration and many times the diameter of the projectile. Infrequently it has been noted that bones located near but not in the missile's path can be fractured by this cavitation phenomenon. The presence of a temporary cavity in bone has been suggested by Harvey, et al. ('62) and Huelke and Darling ('64).

Most previous studies on the effects of high velocity impact on human bone have been limited to clinical descriptions of wartime wounds or museum specimens (LaGarde, 1895; Keith and Hall, '19; and Harvey et al., '62). Because of the sig- nificant differences between animal and human bone in density, strength, and bone architecture, extrapolation of the data from animal subjects to human material is open to question.

In this report, therefore, we will describe the effects of impacts of steel spheres at various impact velocities on the distal end of human femurs.

\section{MATERIALS AND METHODS}

In this study 122 embalmed human femurs were used. The popliteal surface between and slightly above the condyles was the target point. In this region the bone consists of a thin cortical shell enclosing a core of cancellous bone. Throughout the study one-quarter inch diameter, 16.1 grain steel spheres were used as projectiles.

By using steel spheres instead of bullets, the problems of pitch and yaw of the projectile were eliminated. The nondeformable sphere presented the same surface area to the target at all times, whereas the nose of a bullet tends to flatten or mushroom, thereby changing the surface area presented to the target specimen.

The steel spheres were fired from a specially designed helium-operated gun. Projectile velocities between 500 and 1700 $\mathrm{ft} / \mathrm{sec}$ were used in this study by varying

1 This research was supported by U.S.P.H.S. grant AC-00196 from the Division of Accident Prevention Bureau of State Services, and, in part, by the General Research Support grant FR-05383-04 to The University of Michigan Medical School. 
the gas pressure in the gun. The gun, positioned on a rigid table approximately six feet from the securely mounted bone, was fired with a pneumatic valve activated by a Wollensak Control Unit (model WF-301). Behind the bone a projectile recovery box filled with sand and lined with one-quarter inch steel plate prevented the escape or ricochet of the spent projectile. The impact velocity was determined by measuring the time duration of the projectile's passage through two thin electronic grids positioned exactly one foot apart. When the projectile

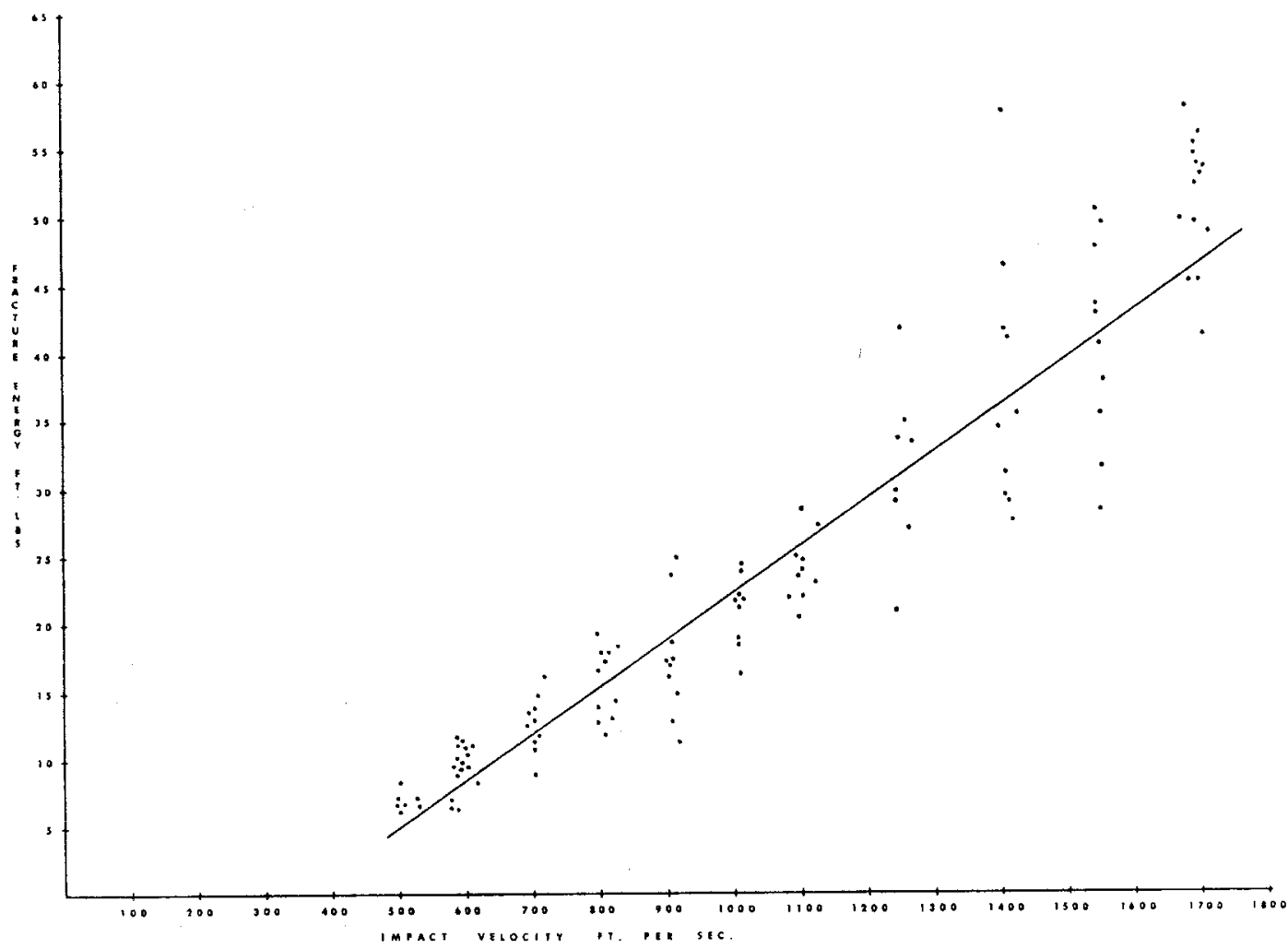

Fig. 1 The relation between impact velocity and energy expanded in fracturing the distal area of human femurs by one-fourth inch steel spheres.

TABLE 1

Average values for distal femoral impacts with one-fourth inch spheres

\begin{tabular}{rcccccc}
\hline $\begin{array}{c}\text { No. of } \\
\text { tests }\end{array}$ & $\begin{array}{c}\text { Entrance } \\
\text { velocity }\end{array}$ & $\begin{array}{c}\text { Exit } \\
\text { velocity }\end{array}$ & $\begin{array}{c}\text { Entrance } \\
\text { energy }\end{array}$ & $\begin{array}{c}\text { Exit } \\
\text { energy }\end{array}$ & $\begin{array}{c}\text { Energy } \\
\text { expended }\end{array}$ & $\begin{array}{c}\text { Percentage } \\
\text { energy } \\
\text { loss }\end{array}$ \\
\hline & $f t / s e c$ & $f t / s e c$ & $f t$-lbs & $f t$-lbs & $f t$-lbs & $\%$ \\
10 & 508 & 175 & 9.2 & 1.6 & 7.6 & 82.6 \\
16 & 590 & 272 & 12.3 & 2.9 & 9.5 & 76.8 \\
10 & 701 & 359 & 17.4 & 4.8 & 12.7 & 72.6 \\
11 & 806 & 453 & 23.0 & 7.5 & 15.5 & 67.3 \\
10 & 905 & 563 & 29.0 & 11.6 & 17.4 & 59.9 \\
10 & 1006 & 624 & 35.8 & 14.1 & 21.7 & 60.7 \\
10 & 1101 & 735 & 42.9 & 19.2 & 23.8 & 55.3 \\
8 & 1250 & 821 & 55.3 & 24.2 & 31.1 & 56.0 \\
11 & 1410 & 957 & 70.3 & 33.1 & 37.2 & 53.0 \\
10 & 1548 & 1111 & 84.9 & 45.4 & 40.8 & 48.0 \\
14 & 1697 & 1198 & 101.9 & 51.0 & 51.0 & 50.0 \\
\hline
\end{tabular}


pierces the first grid, a counter chronograph (Electronic Counters, Inc., model $464 \mathrm{~T}$ ) is activated; when the second grid is pierced, the counter stops. The effect of the paper grids on projectile velocity is demonstrably insignificant.

In order to measure the exit velocity of the projectile, a Dynafax high speed camera (Beckman and Whitley model 326) was used to record the motion of the projectile after bone impact; and two electronic flash units (Beckman and Whitley model 358) were used as light sources. The camera has adjustable framing rates up to 26,000 frames per second. The flash units are also adjustable, generating light pulses for durations of $2.7,5.4$, or 10.8 milliseconds, depending on the framing rate of the camera. For example, a high framing rate required (1) a shorter

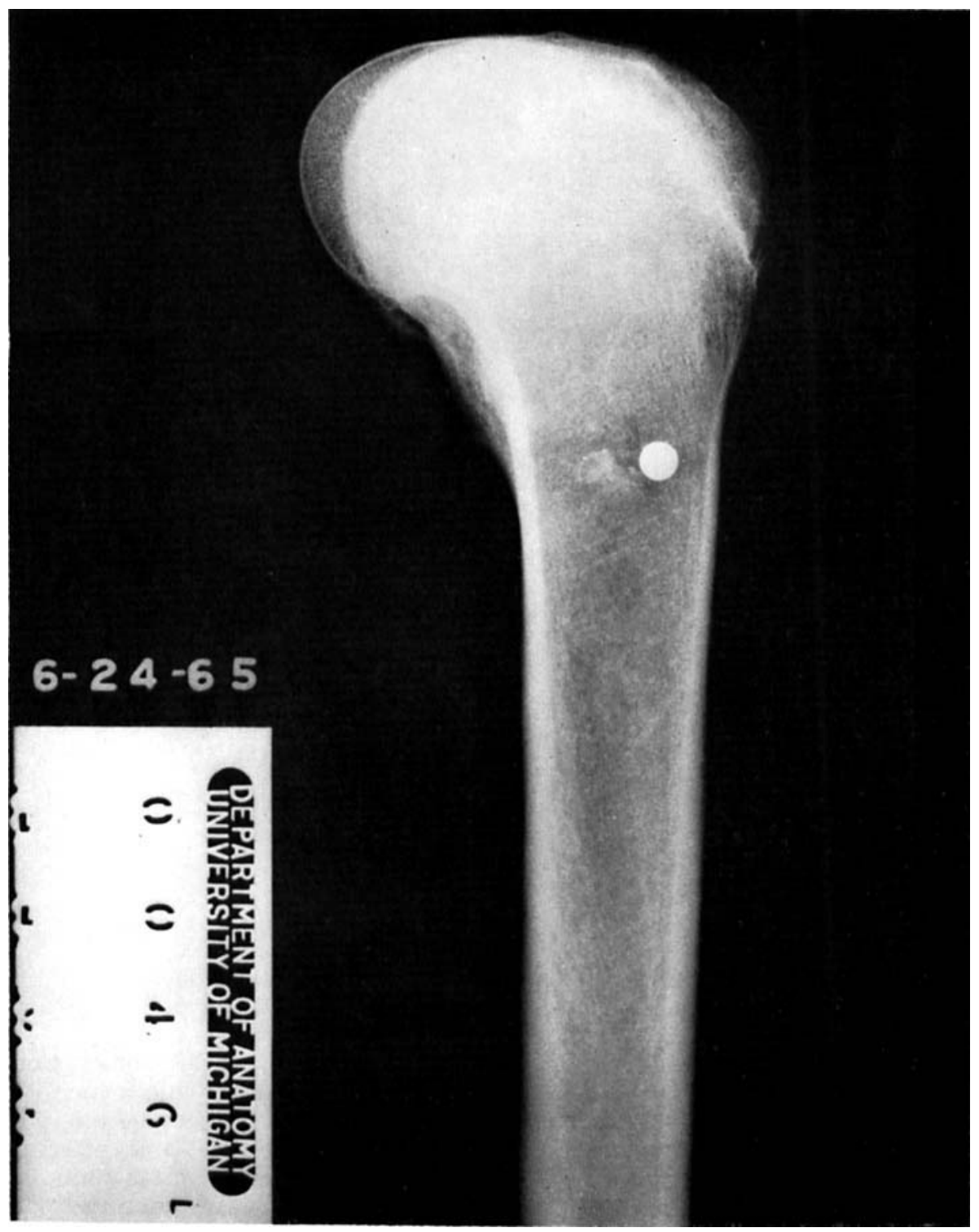

Fig. 2 Radiograph of the distal femur showing a one-fourth inch steel sphere imbedded in the bone. Impact velocity was $483 \mathrm{ft} / \mathrm{sec}$. The projectile entered the bone from the left. 


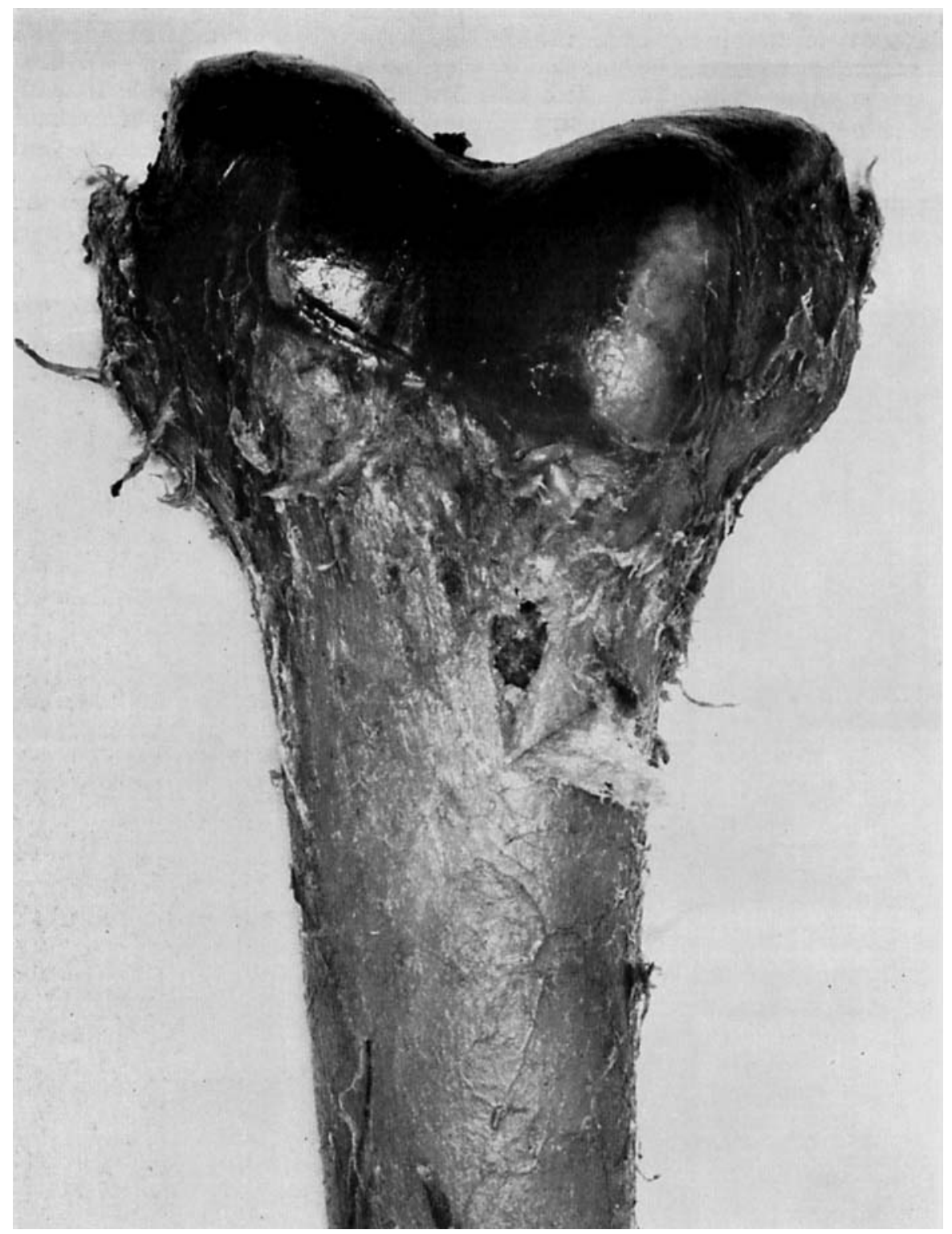

Fig. 3 Exit hole of an embalmed human femur impacted by a one-fourth inch steel sphere at $700 \mathrm{ft} / \mathrm{sec}$.

flash duration to avoid multiple exposures of the film, and (2) a more intense flash to assure that sufficient light reaches the briefly exposed film. After bone impact the projectile passed above a scale standard, two pointed markers set exactly six inches apart. The flash units were synchronized with the event by a Pulse In- terval Generator (Electronic Counters, Inc. model 565T). This generator was activated by the projectile's piercing the second electronic grid, and, after a given delay, it triggered the flash units. By using a camera pulse counter (HewlettPackard model 5512A), a constant readout of the revolutions per second of the 
camera's film carriage was obtained; the readout was automatically stopped when the gun was fired. Using this readout value, calculations of the camera's framing rate at the exact moment of exposure could be made.

Enlarged photographs of the sphere's motion over the scale standard were made and used to measure the distance traveled by the projectile between each frame. The exit velocity of the projectile was then calculated from the camera framing rate and the distance traveled by the sphere between each frame. The residual kinetic energy of the projectile was then computed. The difference between the impact energy and the residual energy represents the amount expended in producing the fracture.

A Fastax high speed camera (Wollensak model WF-1) was used to record the projectile-bone impact phenomenon. This camera was synchronized with gun firing by the WF-301 Control Unit, and the electronic flash units were used as the light source.

\section{RESULTS}

The data indicated that as the impact velocity increases, more energy is expended in producing the fracture (fig. 1). The straight line in figure 1 closely follows the average values of the energy expended at each velocity level, as shown in table 1. In three of the ten specimens at the lowest impact velocity (approximately $500 \mathrm{ft} / \mathrm{sec}$ ) the projectile did not exit from the bone, indicating that this velocity and corresponding impact energy are near the minimum necessary to completely penetrate the distal end of the femur (fig. 2). Damage to the bone at low velocities consisted of entrance and exit holes with minimal cortical fragmentation about the margins of the exit hole (fig. 3 ); no linear or comminuted fractures were found in these specimens. This "drill hole" fracture was only slightly larger than the diameter of the projectile itself. In producing this type of fracture an average energy of 7.6 $\mathrm{ft}-\mathrm{lbs}$ was expended, with a range for the various bones of 6.1 to $9.8 \mathrm{ft}-\mathrm{lbs}$. The high speed film segment (fig. 4) shows the production of this drill hole fracture.

At impact velocities of 800 to $1000 \mathrm{ft} /$ sec the impact energy of the sphere is in- creased, and there was an enlargement of the projectile path through the cancellous bone. Also, the exit hole was noticeably enlarged. High speed films of tests in this velocity range showed large amounts of
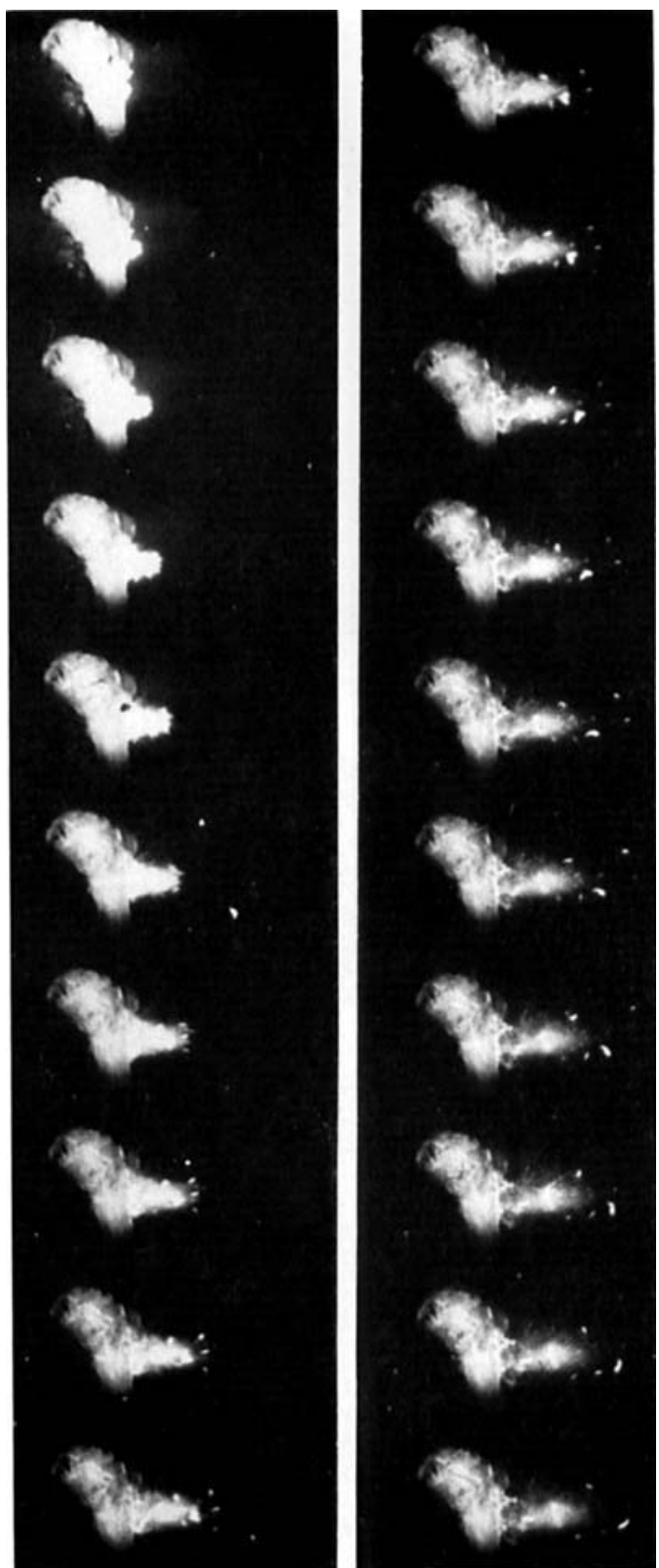

Fig. 4 High speed film segment (14,824 frames/sec) of a one-fourth inch steel sphere impacting the femur shown in figure 3 . The femur is mounted in an inverted position. The sequence begins in the top left frame. 
debris (bone fragments and marrow) being ejected from the exit hole after the projectile had passed through. At 800 $\mathrm{ft} / \mathrm{sec}$ an average energy of $15.5 \mathrm{ft}-\mathrm{lbs}$ was expended in producing the fracture, and at
$1000 \mathrm{ft} / \mathrm{sec}$ the average energy expended was $21.7 \mathrm{ft}-\mathrm{lbs}$.

At an impact velocity of $1400 \mathrm{ft} / \mathrm{sec}$ the projectile path and exit hole were greatly enlarged, and in six of the 11 specimens

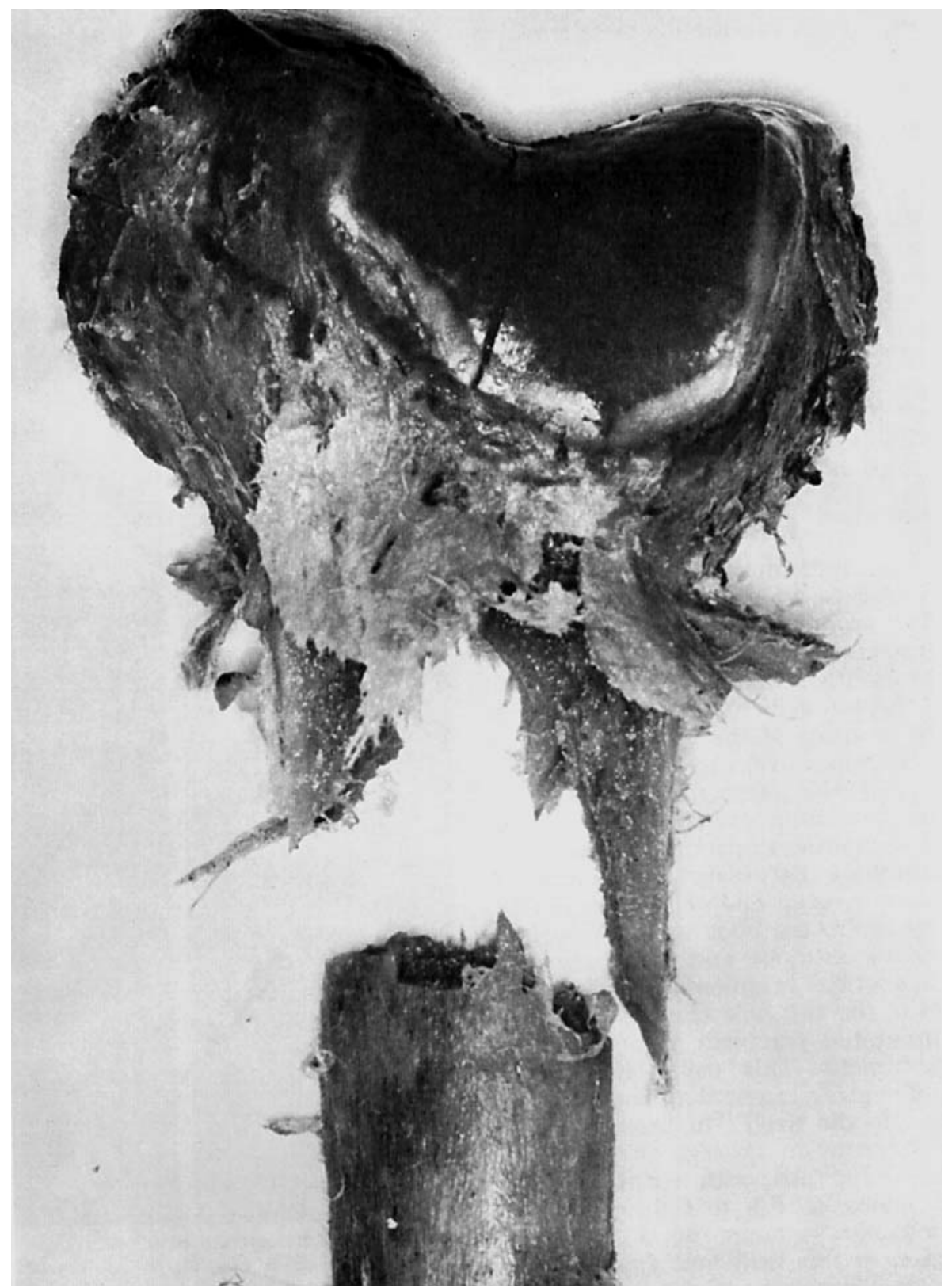

Fig. 5 Human femur impacted by a one-fourth inch steel sphere at $1709 \mathrm{ft} / \mathrm{sec}$. 

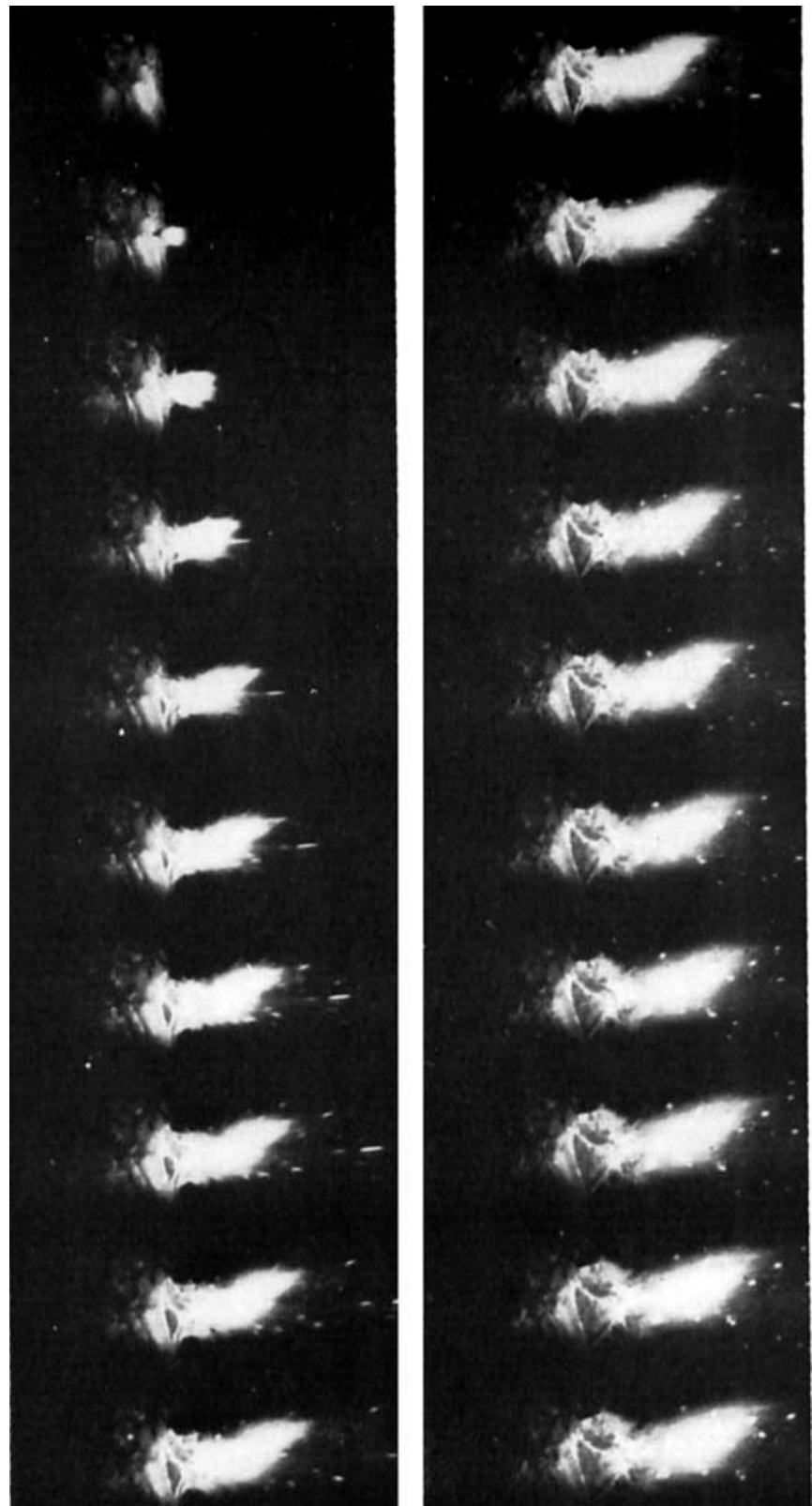

Fig. 6 High speed film segment $(14,856$ frames/sec) of a one-fourth inch steel sphere impacting the femur shown in figure 5. The femur is mounted in an inverted position. The sequence begins in the top left frame.

in this sample there was complete separation of the distal end from the femoral shaft with many comminuted fragments. High speed films of these impacts showed great amounts of cancellous bone frag- ments, marrow, and embalming fluid being explosively expelled from the exit hole. At this velocity an average energy of 37.2 $\mathrm{ft}$-lbs was used in producing the fractures. At the highest impact velocity, $1700 \mathrm{ft} /$ 
sec, almost all bones had extensive comminuted fractures which completely separated the distal end from the shaft (fig. 5 ). In these tests the high speed films clearly demonstrate the enormous explosive effects of such high velocity impacts (fig. 6). The average energy expenditure in producing these fractures was $51.1 \mathrm{ft}$ lbs.

\section{DISCUSSION}

As a projectile passes through soft tissue it imparts radial velocity to the surrounding medium, thereby causing a large temporary cavity. During its brief lifetime the temporary cavity in soft tissue will pulsate several times before it subsides (French and Callender, '62). This displaced tissue may damage other structures some distance from the projectile's path before returning to its original position. The relative lack of elasticity in bone led Herget ('53) to suggest that true cavitation does not occur in bone, but other investigators have noticed an explosive effect on animal bone directly impacted in situ at high velocities (Harvey et al., '62).

The mechanism of the cavitation in bone seems not unlike that in soft tissue: the projectile, after penetrating one cortical plate, encounters the marrow-filled cancellous bone and propels the marrow radially at high velocity, breaking the very thin plates of cancellous bone. When the projectile penetrates the second cortical plate, the exit hole is also enlarged by the cavitation in the cancellous material. Due to the relatively inelastic nature of bone, the temporary cavity thus formed in the cancellous bone also becomes the permanent cavity. Therefore, a relatively large internal cavity may remain whereas in soft tissue it collapses: whether this cavity in bone is called temporary or permanent is only a question of semantics. In addition, as has been observed in soft tissues, the cavitation phenomenon in bone produces an exit hole larger than the entrance hole. In the higher velocity impacts ( 1400 to $1700 \mathrm{ft} / \mathrm{sec}$ ) the cavitation phenomenon produced an explosion of the tissue, destroying the greater portion of the cancellous bone and fragmenting the surrounding cortical bone.

Examination of femurs after impact disclosed that some had little embalming fluid or marrow within the cancellous bone (due to excessive drying). In these bones the cavitation effects were diminished and the energy expended in producing the fractures was lower than average for the specific impact velocity. Furthermore, in some preliminary studies of high velocity impacts to dried and degreased femurs, it was found that drill hole fractures were produced at the same impact velocities that produced extensive damage to the marrow-filled cadaver specimens. In the dry femurs there is no mass of tissue or fluid to be radially displaced; thus without the effects of cavitation, extensive fractures, as described above, are not produced.

At the lower impact velocities the radial displacement of the cancellous material is minimal: little cavitation is noted in the velocity range below $800 \mathrm{ft} / \mathrm{sec}$. Callender and French ('35) indicated that the degree of destruction caused by identical projectiles is significantly dependent upon the density of the tissue and upon the impact velocity of the projectile. In more dense material and/or with greater impact velocity more tissue destruction is found. In a fluid system such as soft tissues, resistance to penetration increases with the impact velocity; so if the impact velocity is increased sufficiently the resistance of less dense tissues approaches the resistance offered at lower impact velocities by more dense tissues. For example, fluid-filled viscera, blood vessels, and other soft tissues such as muscle will literally explode when impacted by a high velocity projectile. Since cancellous bone is actually filled with a soft tissue, the marrow, we feel that the explosive nature of the femoral fractures from impacts at the higher velocities is not unlike that seen in impacts to soft tissues.

The linear increase in the energy expended to produce fractures as a function of impact velocity is due to the resistance of the material. This resistance is not only dependent upon the hardness and elasticity of the tissue but also on its density. At velocities above that necessary for penetration the projectile will dissipate a greater proportion of its energy in the tissue as the impact velocity increases because of increasing resistance. 
Biological variation between the femurs is well demonstrated in figure 1. At each impact velocity there is a scattering of the data points. This is not due to errors of measurement or recording, for calculations show that our total error is $3 \%$ or less. Four important parameters influence this biological variation. One is the total thickness of the bone at the impact point. Micrometer measurements of the specimens along the projectile path indicate that in the thicker specimens more energy is expended to produce the fracture. The second factor is the thickness of the cortical bone at the points of impact and exit of the missile. The third variable is the density of the cortical bone and of the enclosed cancellous bone. The fourth factor is the amount of marrow and/or embalming fluid within the cancellous spaces. These parameters then can produce variations in the amount of energy expended by the projectile at a given impact velocity.

Preliminary studies using fresh unembalmed human femurs have shown that at the various impact velocities the data points fall within the range of those plotted in figure 1 for embalmed bone. Thus there do not appear to be any significant differences between embalmed and unembalmed human bone in response to high velocity impact.

\section{LITERATURE CITED}

Callender, G. R., and R. W. French 1935 Wound ballistics: Studies in the mechanism of wound production by rifle bullets. Military Surg., 77: 177-201.

Coates, J. B., and J. C. Beyer 1962 Wound Ballistics. Office of the Surgeon General, Department of the Army, Washington, D. C.
Dziemian, A. J., J. A. Mendleson and D. Lindsey 1961 Comparison of the wounding characteristics of some commonly encountered bullets. J. of Trauma, 1: 341-353.

French, R. W., and G. R. Callender 1962 Wound Ballistics. Ed. by J. B. Coates and J. C. Beyer. Office of the Surgeon General, Department of the Army, Washington, D. C. Chapter II, 91-142.

Grundfest, H. 1945 Penetration of Steel Spheres into Bone. Missiles Casualty Report no. 10, National Research Council, Division of Medical Science, Office of Research and Development.

Harvey, E. N., J. M. Korr, G. Oster and J. H. McMillen 1947 Secondary damage in wounding due to pressure changes accompanying the passage of high velocity missiles. Surgery, 21: 218-239.

Harvey, E. N., and J. H. McMillen 1947 An experimental study of shock waves resulting from the impact of high velocity missiles on animal tissues. J. Exper. Med., 85: 321-328.

Harvey, E. N., J. H. McMillen, E. G. Butler and W. O. Puckett 1962 Wound Ballistics. Ed. by J. B. Coates and J. C. Beyer. Office of the Surgeon General, Department of the Army, Washington, D. C. Chapter III, 143-236.

Herget, C. M. 1953 Surgery of Trauma. Ed. by W. F. Bowers. J. B. Lippincott Co., Philadelphia. Chapter 25, 494-510.

Horsley, V. 1894 The destructive effects of projectiles. Notices of the proceedings of the Royal Institute of Great Britain, 14: 228-238.

Huelke, D. F., and J. H. Darling 1964 Bone fractures produced by bullets. J. of For. Sci., 4: 461-469.

Keith, A., and M. E. Hall 1919 Bones showing the effects of gunshot injuries, in the army medical collection now on display in the Museum of the Royal College of Surgeons of England. Brit. J. of Surg., 24: 537-565.

Krauss, M. 1957 Studies in wound ballistics: Temporary cavity effects in soft tissues. Military Med., 4: 221-231.

LaGarde, L. A. 1895 Gunshot wounds. Report of the Surgeon General of the Army, 73-95. 